\title{
Coevolution of climate, demography and food systems in North and South America
}

\author{
Jacob Freeman', A. Gil², M.L. Cárdenas ${ }^{3}$, D.A. Byers', M.B. Cannon'1, J.M. Capriles ${ }^{4}$ and C. Latorre ${ }^{5}$
}

Logan, USA, 8-11 November 2016

\begin{abstract}
One of the less well-understood problems in paleoscience is the role of climate as a modulator of long-term changes in human demography, and, in turn, how changes in human demography influence climate because demography also determines how individuals choose to modify ecosystems. Our workshop compared the long-term interaction between climate, human population change and the organization of social systems to understand the coevolution of Social and Ecological Systems (SES). The feedbacks between climate, ecosystems and social systems may lead to threshold changes in the organization of SES (Anderies et al. 2013). Paleoscience is critical for understanding how and when interactions between climate, ecosystems, and human systems reach threshold-state changes. Such understanding is important because contemporary SES must adapt to population growth and climate change, and insights gained from past SES may inform sustainable development in the contemporary world.
\end{abstract}

Our workshop compared the past responses of SES to climatic and vegetation changes in case studies from North and South America. Our comparison revealed two patterns. First, after 3000 BP, human populations spiked in all case studies, though the timing of this spike varies. Why this occurred is an open question, and we discussed potential relationships between demography, climate change and local changes in vegetation. Understanding why this population growth occurred and how humans adapted to increasing demographic pressure is a critical area for future research. Second, among our case studies, populations declined, at a regional scale, after $800 \mathrm{BP}$. The timing of the decline is coincident with the transition to the Little Ice Age (700-100 BP). Declines in population and associated reorganizations of social practices take place in North America around $750 \mathrm{BP}$ and not until 550 BP in our South American cases (Fig. 1). A major issue raised during our workshop is how the global transition to the Little Ice Age may have affected the ecosystems in each case study differently.

Two questions emerged from the comparison of our case studies: (1) Why does the increase in population vary from region-to-region? (2) Which factors best explain the threshold decline in population after 800 BP? We discussed the usefulness of the concept of robustness-fragility tradeoffs. Robustnessfragility tradeoffs occur when a set of strategies allow individuals to consistently achieve a goal, like biomass harvested per day, but these strategies set up a system for cascades of abrupt change and/or failure (Anderies

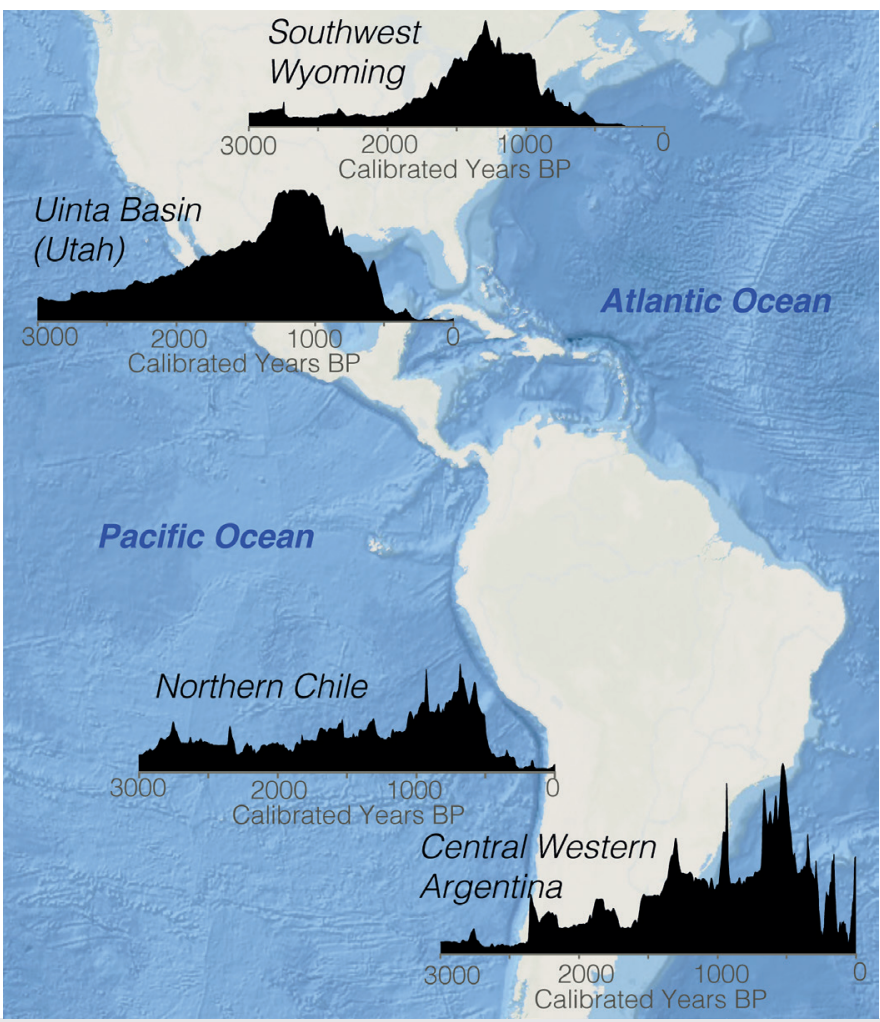

Figure 1: Summed probability distributions of radiocarbon dates from four regions in North and South America. The summed probability time-series is an estimate of population size over time. The proxy is for prehistoric societies only. The decline in dates after $250 \mathrm{BP}$ is a function of the increasing prevalence of historical records. Northern Chile dates published in Gayo et al. (2015).

2015; Csete and Doyle 2002). Using the robustness-fragility concept, we proposed that investments in strategies that reduced variation in the production of food, in response to population growth, set up many SES for a major reorganization in response to the global climate shock of the Little Ice Age. The severity of the reorganization observed is a consequence, we speculate, of the ability of societies to maintain diverse social strategies and use diverse ecosystems to adapt to population growth. The role of variation in climate regimes, ecosystems and social systems in controlling the appearance of critical thresholds in SES is a major area for future research identified by our group.

In the end, we developed a new working group called PEOPLE 3000 (PalEOclimate and the PeopLing of the Earth), composed of paleoecologists, archaeologists, ecologists and mathematicians. The goal of PEOPLE 3000 is to describe and explain the role of global climate change in the exponential increase of population between 3000 and $800 \mathrm{BP}$, and variation in the subsequent magnitudes of decline of population after $800 \mathrm{BP}$. This network will explore how climate impacts human socio-economic development over the long term and the tradeoffs associated with human adaption to climate change and population growth. Our work is specifically concerned with the potential for robustnessfragility tradeoffs associated with strategies for coping with climate change and population growth, and how such tradeoffs may set up human systems for failure in the face of global climate shocks.

\section{AFFILIATIONS}

'Anthropology Program, Utah State University, Logan, USA

${ }^{2}$ CONICET-IANIGLA/San Rafael; Technological National University (UTN-FRSR); Mendoza (Argentina) ${ }^{3}$ Department of Geography and Environmental Science, University of Reading, UK

${ }^{4}$ Department of Anthropology, The Pennsylvania State University, USA

${ }^{5}$ Department of Ecology, Pontifical Catholic University of Chile, Santiago, Chile

\section{CONTACT}

Jacob Freeman: Jacob.freeman@usu.edu

\section{REFERENCES}

Anderies JM et al. (2013) Ecol Soc 18: 8

Anderies JM (2015) Bull Math Biol 77: 259

Csete ME, Doyle JC (2002) Science 295: 1664-1669

Gayo EM et al. (2015) Quat Int 356: 4-14 